\title{
A abordagem narrativa como recurso avaliativo de políticas públicas
}

\author{
Raul da Fonseca Silva Thé \\ João Bosco Feitosa dos Santos ${ }^{2}$
}

\section{RESUMO}

Este artigo busca apresentar como uma abordagem das ciências sociais e, especialmente, da sociologia, ampla em seu escopo e que prima pela narratividade dos sujeitos inseridos em determinados contextos, pode ser utilizada como metodologia de avaliação de políticas públicas. Para tanto, é exposta de forma resumida a utilização desta abordagem em uma pesquisa sobre uma política de microcrédito, o programa Crediamigo. Por fim se ressaltam os indicativos da abordagem narrativa na prática da avaliação, em seus limites e possibilidades, bem como o que auxiliou a desvendar da citada política e as evidências produzidas para possíveis reformulações.

Palavras-chave: Abordagem narrativa; Metodologia; Avaliação; Microcrédito.

\begin{abstract}
This article seeks to present as an approach to the social sciences, and especially to sociology, which is broad in scope and which excels by the narrativity of the subjects inserted in certain contexts, can be used as a methodology for the evaluation of public policies. In order to do so, the use of this approach is summarized in a research on a microcredit policy, the Crediamigo program. Finally, the indicative of the narrative approach in the practice of the evaluation, in its limits and possibilities, as well as

1 Mestre em Sociologia pelo Programa de Pós-Graduação em Sociologia da Universidade Estadual do Ceará (PPGS/UECE) e Bacharel em Ciências Sociais pela Universidade Federal do Ceará (UFC). E-mail: raulsilvathe@gmail.com.

2 Doutor em Sociologia pela Universidade Estadual Paulista (2008) e Professor permanente da Universidade Estadual do Ceará-UECE, no Programa de Pósgraduação em Soiologia-PPGS. E-mail: bosco_feitosa@yahoo.com.br.
\end{abstract}


what helped to unveil the mentioned policy and the evidence produced for possible reformulations are emphasized.

Keywords: Narrative approach; Methodology; Evaluation; Microcredit.

\begin{abstract}
As ciências sociais e humanas, nas últimas décadas, têm se inclinado mais e mais às subjetividades e intersubjetividades, por isso a noção de sujeito vem sendo retomada e se insere no centro das discussões e problemáticas. Esta incorporação se dá não só na dimensão do escopo epistemológico para coleta de dados, mas, também, como uma chave metodológica das análises sociológicas. $\mathrm{O}$ que a contrapõem à predominância de perspectivas centradas nas estruturas, sínteses teóricas e da metodologia pela metodologia.
\end{abstract}

Neste recorte, se apresentam diversas abordagens que passam a ter proeminência por colocar o sujeito social neste lugar analítico. Propondo, assim, possibilidades de interpretação de micro e/ou de médio alcance suscitadas pelas histórias e narrativas de vida, pela biografia e pela composição dos mundos da vida e das sócio-lógicas. Destacam-se as preocupações por compreender os sentidos, as significações e ressignificações resguardadas nas relações sociais; os processos de mudança; e, como algumas biografias sintetizam intervenções econômicas e políticas (pública/social) (ALVAREZ, 2007; GUSSI, 2004; 2008; MONTAGNER, 2007; 2009; KOFES, 2004; RODRIGUES, 2004; SANTOS, 2002; THÉ, PEREIRA e GUSSI, 2014).

Dentre as formulações que abordam o sujeito destaca-se a abordagem narrativa, por aprofundar a observação dos impactos e reverberações das ações e lógicas públicas e privadas nos contextos em que os pesquisadores buscam analisar, interpretar e avaliar. Neste tópico salientam-se as possibilidades indicativas à avaliação, uma vez que a abordagem narrativa se evidencia como uma perspectiva teórico- 
metodológica que desenha pesquisas alto-contidas do ângulo horizontal ou no sentido do alcance, entretanto que se expandem no sentido vertical ou na direção do aprofundamento hermenêutico e nos sentidos expostos pelos sujeitos que constituem o campo operacional da política pública.

O texto a seguir se compõe pela descrição da abordagem narrativa e aponta para as possibilidades que traz para a avaliação de políticas públicas. Em seguida será exposta a utilização desta abordagem em uma pesquisa empírica sobre uma política de microcrédito. Por fim, aponta-se nas considerações finais tanto uma apreciação sobre a abordagem teórico-metodológica narrativa quanto as evidências sobre a citada política.

\section{A abordagem narrativa e suas possibilidades avaliativas: uma proposta metodológica}

Como exposto acima, a abordagem narrativa compõe-se por uma multiplicidade de apropriações, já que esta oferta a possibilidade tanto de adentrar no processo de subjetivação dos regramentos estruturais quanto de realizar o duplo movimento de objetivar a subjetividade e subjetivar a objetividade (DOSSE, 2009). Dentre as apropriações dessa abordagem se pontuam a (auto)biografia formativa, ${ }^{3}$ a etnobiografia, ${ }^{4}$ as histórias de vida ${ }^{5}$ e a apropriação eliasiana ${ }^{6}$ de um curso de vida.

3 Para esta a processualidade da construção pessoal e a valorização da experiência vivida contada importam, e encaminham a autocompreensão dos sujeitos. Destaco os trabalhos de Batista (2010), Garnica (2010), Lechner (2010) e Rosito (2010).

${ }^{4}$ Entre a biografia e a etnografia, preocupa-se em captar as subjetividades hodiernas e entender a condição humana, enquanto antepõe sentidos e ações, valoriza a reflexividade discursiva do interlocutor e aponta para a dimensão diacrônica dos sujeitos. Com relevo no trabalho de Gosselin e Marques (2014).

${ }^{5}$ Capta o homem social por meio de relatos, possibilitando a exposição das gramáticas sociais e culturais, o processo dialético de constituir a sociedade e ser 
Todas se caracterizam por privilegiar falas e ações êmicas, as alteridades, os possíveis e o reconhecimento das contradições; buscar ultrapassar o caráter individual e singular, relacionando as idiossincrasias e as condições socioculturais; apontar para as assimetrias de poder, os processos de mudança social e os movimentos de circulação simbólica; e, certa proposição sociopolítica. Resguardam, portanto, não só a faculdade metódica e epistêmica, mas, também, cognitiva e política que constituem a abordagem narrativa.

Além das apropriações já citadas, convém realçar a noção teórico-metodológica de trajetória $^{7}$ como a mais abalizada para a realização do processo avaliativo de políticas públicas por incorporar as ideias de inconstância, fragmentação e sinuosidade tanto das vidas dos participantes quanto das políticas públicas, bem como dos contextos em que elas estão inseridas. Dessa forma, ao se falar em trajetória não se pretende denotar algo parado, fixo ou um fato estanque no tempo, mas sob a perspectiva de como as narrativas e as políticas públicas são reconstruídas frequentemente e como adquirem novos significados. Mediante esse olhar as experiências da e com a política pública são relevantes para compreender a atuação da mesma, uma vez que essas experiências se elaboram pela cultura e pela produção de sentidos. A

constituído por ela abre-se para os possíveis (relação entre o vivido e os vivíveis) e para o reconhecimento das contradições, sem desconsiderar a diferença entre relato e realidade, buscando, assim, ultrapassar o caráter individual e singular. Temática explorada em Becker (1994), Bertaux (2005), Born (2001), Debert (1986), Gibbs (2009), Gussi (2004), Gonçalves (2008), Martins (1996; 2011), Mendes (2004), Rigotto (1999), Rivas Flores (2011) e Velho (1989).

${ }^{6}$ Elias (1995) busca descrever o contexto de um preciso curso da vida e traça um quadro das pressões sociais, tomando o ponto de vista e os significados do sujeito, em seus anseios e experiências. Neste foco observa em que estágio do processo civilizador o padrão social de comportamento e de sentimento se localiza, quais as assimetrias de poder em determinada época, enquanto formula um modelo verificável das configurações de relações. Ver Barreira (1996).

7 Com destaque nos trabalhos de Barreira (2002), Bourdieu (1996; 2004; 2005), Gussi (2008; 2014), Kofes (1994; 2001; 2007), Montagner (2007; 2009), Ortiz (1983), Santos (2002) e Thé, Pereira e Gussi (2014). 
trajetória a que nos referimos se diferencia, assim, de uma path dependence (subordinação à trajetória) (BANDEIRA, 2008; BOURDIEU, 1996; BONDÍA, 2002; KOFES, 2001; THOMPSON, 1991).

Apontada a pluralidade do campo da abordagem narrativa, cabe indicar que o uso de narrativas e, especificamente, da trajetória, também se vincula com os vários dizeres e fazeres do campo da política pública: sejam as narrativas dos participantes e/ou consumidores sejam dos gestores, ou mesmo dos demandantes. Todas essas narrativas são passíveis de levar a cabo uma interpretação da política pública que se pretende avaliar, podendo esta avaliação ser centrada em um desses pontos da experiência ou de forma a dialogar entre essas narrativas (GUSSI, 2014; WORTHEN, SANDERS e FITZPATRICK, 2004).

Dessa maneira a abordagem compreensiva sobre políticas públicas se torna central para a presente proposta metodológica de avaliação, uma vez que esta tem como foco a percepção das narrativas e trajetórias dos sujeitos referentes à política pública para entender os processos ocorridos na trajetória da própria política. Por isso, a base desta proposta está vinculada a compreensão de Rodrigues (2008) de que uma visão contextual e multidimensional da política ou da instituição pública se depreende dos aspectos culturais ensejados pela construção metodológica de uma trajetória institucional. Interpretação que Sousa (2014) concorda ao propor uma visão panorâmica que prima por sentidos e significados. Constituindo, assim, um processo avaliativo que se realiza sob uma perspectiva interpretativa e hermenêutica, em que as possibilidades de significados diversos e, possivelmente, diferenciados ou contraditórios ao do discurso oficial se ressaltam e se expandem. Dessa forma, se diferencia totalmente do modelo técnico-formal de observação/avaliação de políticas públicas que tem uma episteme funcional e positiva, além de desconsiderar os agentes sociais, os 
contextos sociopolíticos e culturais dos níveis de realização da política pública, além das contradições a eles inerente (GUSSI, 2014).

Assim, a abordagem narrativa como recurso avaliativo tem um viés prático micropolítico por sua responsabilidade estratégica de intervenção e por, com efeito, se desenvolver in loco/in situ e, desse modo, in vivo também. Ou seja, no local e com a vivacidade experiencial que circundam a operacionalidade da política pública. Com uma forte característica relacional-subjetiva, uma vez que a apreensão do social possibilita e se dá na interação com o outro e no compartilhamento do drama da vida cotidiana. Formula, então, um conhecimento diferenciado, em seu projeto e em sua plataforma política, que amplia os horizontes metodológicos, analíticos e também políticos da própria avaliação. Isso porque carrega em si um cunho sociopolítico e cultural que ressalta a dimensão constitutiva da experiência de si (dos sujeitos dispostos no campo) e da política pública (das institucionalidades e processualidades deste campo), enquanto o processo avaliativo do campo público, em seus saberes e em suas relações de poder, se torna uma necessidade fundante (BRANDÃO, 2007; CICOUREL, 1990; GUSSI, 2014; ORTIZ, 1983; PRATA, 1999; SÁ, 2009; WEBER, F., 2009).

Desse modo, os níveis de análise que a abordagem narrativa traz para a metodologia avaliativa são ao mesmo tempo micro, meso e macro. Uma vez que enquanto as narrativas e trajetórias sujeitos (gestores, demandantes e participantes) recebem um tratamento de nível micro, os contextos e as lógicas de formulação e reformulação das políticas públicas são tratados no nível macro. Enquanto no nível meso está a política a ser avaliada, seu operativo-institucional e os encaminhamentos da mesma. Sinteticamente ocorre uma ligação entre o socioestrutural, em seu marco macro e objetivo, e o sociossimbólico, no micro e subjetivo, apontando para uma margem sociopragmática, no marco meso e cotidiano da política pública, mas, também, da vida social. (NOBRE, 2012).

Para tornar operativa esta proposta metodológica e razoável a realização de avaliação de políticas públicas, convém indicar que a 
abordagem narrativa requer uma inclinação destacada aos procedimentos qualitativos de coletas de dados. Com relevo especial na produção e condução de entrevistas em profundidade e a posterior construção das trajetórias dos sujeitos que (se) narraram. Ao momento posterior cabe o tratamento dos dados, uma vez que tanto as vidas quanto as políticas públicas estão circunscritas a ressignificações, a perspectiva hermenêutica toma sentido reforçado e mediante seu uso se pode compreender a relevância dos deslocamentos dos agentes sociais no espaço sociopolítico. Por isso a construção analítica da trajetória da política requer duas dimensões concomitantes: (1) narrativa, baseada nos trajetos dos sujeitos escolhidos pelo desenho avaliativo; e (2) descritiva, dos contextos (transnacional, nacional, municipal, local e do cenário imediato), dos textos (percepções, sentidos, significados, símbolos e relações) e, também, dos pretextos (intencionalidades e interesses explícitos e implícitos na dinâmica da política pública) apanhados no processo da investigação avaliativa.

Uma diferença fundamental está na composição que o campo de apuração avaliativa toma quando do uso da abordagem narrativa como recurso avaliativo. Isso porque cada um dos sujeitos que se dispuserem a interlocução com o avaliador deve ser tratado como todo um campo de investigação, que, ao mesmo tempo, resume e expande os caracteres próprios de um campo de pesquisa (estranhamento, contraste, negociações, explicações e a vivência do pesquisador de ser aceito como interlocutor) e da relação intersubjetiva pesquisador/avaliadorpesquisado. O que revela, também, uma perspectiva e preocupação ética no como tratar os interlocutores que narram, uma vez que a abordagem narrativa como metodologia se compromete em tomar os sujeitos como agentes e co-atores da política pública em que estão inseridos.

Finalmente, cabe pontuar que a perspectiva geral desta indicação da abordagem narrativa das ciências sociais como recurso 
avaliativo de políticas públicas se relaciona e aceita os desafios prementes da inovação metodológica da avaliação, por meio de novos formatos, novas técnicas e metodologias, e que paulatinamente gestem novas epistemologias. Além disso, convém realçar um traço particular da abordagem narrativa que ao invés de revelar o sujeito salienta fenômenos sociais, simbólicos e pragmáticos mediante inflexões, diferenças e interpretações e que, por isso, se usada em processos avaliativos de políticas públicas tende a encaminhar a reconciliação entre a observação e a reflexão no contexto da avaliação (GUSSI, 2014).

\section{A abordagem narrativa e a política de microcrédito do Banco do Nordeste, o Crediamigo}

Para apresentar a aplicação da abordagem narrativa sobre uma política pública no intuito de avaliá-la, buscaremos seguir os passos indicados na seção anterior. Ou seja, primeiramente apresentaremos a política pública a ser avaliada, depois os elementos descritivos, em seguida o desenho e execução da pesquisa avaliativa. De modo que tentaremos expor todo o escopo desta aplicação metodológica, que sendo cara à sociologia, apresenta-se como um recurso ao campo de políticas públicas.

O Programa Crediamigo ${ }^{8}$ é uma ação microcreditícia pioneira de um banco público do Brasil e a única iniciativa mundial bem-sucedida de um banco público/estatal. Sendo a política pública de Microcrédito (Urbano) Produtivo Orientado do Banco do Nordeste, o maior banco de desenvolvimento regional da América Latina. Hoje abrange toda a área de atuação do Banco (Região Nordeste, Norte de Minas Gerais e Espírito Santo, além de Brasília, Belo Horizonte e Rio de Janeiro), contando com

\footnotetext{
${ }^{8}$ No intuito de estudar “o governo em ação” (SOUZA, p. 18, 2003; p. 22, 2006) a presente pesquisa se localiza, no ciclo das políticas públicas, no nível da implementação e sobre o contato da política com a vida das participantes.
} 
mais de dois milhões de clientes ativos. Desses aproximadamente um terço reside no estado do Ceará. Estado que, juntamente com sua capital (Fortaleza), foi o que primeiramente recebeu o Crediamigo e têm em sua área o maior número absoluto de clientes.

Uma de suas características básicas é a garantia relacionada ao aval solidário para os empréstimos, esses variam de $\mathrm{R} \$ 100,00$ a $\mathrm{R} \$$ 15.00o,oo, de acordo com a necessidade e o porte do nanonegócio. Com grande êxito, e referendado no âmbito internacional, é a maior experiência de microcrédito da América do Sul. Seu tamanho pode ser delineado pela oferta de mais microcrédito que os demais programas do Brasil juntos. Por isso, seu modo de conceder crédito foi desdobrado para a perspectiva rural, no Agroamigo, e ambos serviram como modelo para o Programa Nacional Crescer (BANCO DO NORDESTE, 2019).

Esta política pública é o resultado de um acúmulo organizativo de longa duração. Se no cenário internacional houveram diversas experiências microcreditícias nos últimos séculos, foi na década de 1970 que o Grameen Bank e Yunus se tornaram modelo base da operacionalização do microcrédito no mundo. Ocorrendo nesse período por estar intimamente vinculado com a perspectiva das "necessidades fundamentais" e as possibilidades de incluir (ou ao menos integrar) progressivamente os pobres ao sistema econômico, ventilada pela Organização Internacional do Trabalho e do Banco Mundial. Mesmo com crises no mercado microcreditício ("subprime dos pobres") 9 diversos países investem fortemente nesse mercado (KARNANI, 20o8; LAGNEUYMONET e MADER, 2013; RIST, 2002).

Com a replicação do modelo Grammen Bank dois modelos ficaram evidentes: (1) o modelo asiático, concede principalmente

\footnotetext{
${ }^{9}$ Crises do microcrédito ocorreram na Bolívia (2000), no Marrocos (2007), na Bósnia e Herzegovina, na Nicarágua e no Paquistão (2008) e na Índia (2005 e 2010). Ver Lagneu-Ymonet e Mader (2013).
} 
nanonegócios rurais, situa o foco em uma população de baixa renda mais profunda e, consequentemente, têm consigo grandes carteiras de clientes: uma média de $130 \mathrm{mil}$, enquanto a latino-americana tem $30 \mathrm{mil}$; (2) o modelo latino-americano, ocorreu por um processo de upgrading $^{10}$ de organizações não governamentais (ONG’s), ou seja, da transição de ONG's para a instituição microfinanceira. A característica principal e inovadora destas foi o aprimoramento da concessão do microcrédito urbano. Outra característica marcante deste modelo foi o apoio reiterado da Acción Internacional.

No Brasil as experiências de microcrédito existem desde a década de 1950, mas foi a década de 1990 que ensejou o Crediamigo. Alguns dos incentivos ao surgimento dessa política pública estão: no diagnóstico, de 1997, de uma soma de 23,3 milhões de pobres e indigentes na Região Nordeste brasileiro; na indicação de que todo um público não teria sequer a possibilidade de ser empregado (os “inempregáveis", segundo o presidente Cardoso); e, fundamentalmente, a aplicação no Banco do Nordeste da lógica neoliberal. Diferente do modelo latinoamericano ao Crediamigo aplicou-se o modelo de downscaling ${ }^{11}$ muito por conta de ser uma metodologia funcional na busca de atingir os clientes estimados como demandantes e, em segundo plano, do uso da metodologia de grupos solidários, da qual o Banco não tinha experiência de campo (DIMENSTEIN, 1997; GARCIA, 2010; NERI et al., 2008; NITSCH e SANTOS, 2001; TEIXEIRA, 2008; THÉ, 2014).

Sendo esses os elementos descritivos mais relevantes, cabe agora apresentar o desenho da pesquisa avaliativa. A primeira escolha feita foi a de que

${ }^{10}$ Um caminho possível da operacionalização do microcrédito, que se relaciona com a criação de uma instituição microfinanceira regulada por uma ONG. Esta instituição sem fins lucrativos é fortalecida e depois é transformada em uma instituição lucrativa, com um banco, por exemplo (NERI et al., 2008).

${ }^{11}$ Modelo que consiste em instituições financeiras já estabelecidas e com um conhecimento prévio (seja do público, seja da região seja, ainda, da oferta de crédito) passarem a abarcar clientes no nível microeconômico. 
universo de sujeitos inseridos na política pública seria buscado. Diante de uma bibliografia nacional e internacional sobre o microcrédito que prioriza análises e avaliações na perspectiva das instituições microfinanceiras escolhemos os participantes ou, no contexto do Crediamigo, os clientes. Além de questionar criticamente os cases de sucesso do microcrédito como uma parte diminuta da história e não toda ela (ARAÚJO e LIMA, 2014; WORTHEN, SANDERS e FITZPATRICK, 2004).

Em seguida, a escolha do locus investigativo. Esse se deu na área de atuação da Unidade Montese do Crediamigo, em Fortaleza (Ceará), por ser a unidade pioneira e que o lançou. O mapeamento da unidade se deu pelo contato direto com os participantes, abarcados por essa unidade, em seus negócios e durante os anos de 2015-2017. No terceiro passo, a prospecção e o recrutamento das entrevistas. Esse se realizou por meio de contato direto e após o primeiro contato com os participantes pedimos que nos indicasse o entrevistado seguinte, o fizemos nos utilizando da técnica de amostragem não probabilística - conhecida como bola de neve (snowball sampling) - de modo linear e assumimos a premissa metodológica da saturação, como garantia de objetividade na utilização da abordagem narrativa. Nesse momento foi escolhida a noção teóricometodológica da trajetória como forma de melhor interpretar os dados das sete narrativas reiteradas e aprofundadas que foram recolhidas e construídas compreensivamente. (VINUTO, 2014).

As entrevistas em profundidade buscaram, mediante as narrativas dos clientes conhecer e assimilar: as trajetórias pessoais e familiares dos participantes interlocutores; as prioridades na vida; como iniciaram os negócios; qual a relação com o crédito, com o Crediamigo, os colegas de grupo solidário e o Banco do Nordeste; e, que impactos sobre a economia cotidiana (renda, consumo e endividamento) apresentados com o microcrédito. Dados que auxiliaram na construção metodológica das trajetórias de cada uma das vidas dos participantes, bem como a 
composição da trajetória coletiva destes participantes e da própria política.

Desse modo, a abordagem narrativa foi utilizada de modo a construir e reconstruir trajetórias que mediassem o coletivo e o individual, a partir do segundo. De forma que revelassem uma outra perspectiva para olhar a citada política pública. Para tanto, a pesquisa foi encaminhada, como dito antes, por entrevistas aprofundadas com sete nanoempreendedoras, que, posteriormente, foram tratadas para a concepção de trajetórias lógicas, e não necessariamente lineares.

Essas trajetórias apontaram para um perfil, entre as interlocutoras, que indica: (1) a vulnerabilidade como uma constante, exposta pela necessidade de migrar muito cedo por necessidade:

vim pa Fortaleza, achando, assim, que quando eu saí de lá,
vim pa Fortaleza, achando 'Ah, outra vida', você... sabe?, a
gente sai do interior, vai pra otro estado, né?, estado não que
é perto, né?, de Rio Grande pra cá, só é extremando Ceará
com Rio Grande do Norte, né?, ai a gente sai pra vê se...
procurar oto recurso melhó, né?, mas continua a mesmas
coisa, porque foi trabalhar em uma casa de família também
(Interlocutora $K$.).

(2) A família se configura como ponto de partida (demonstrativo das condições prévias de empobrecimento) e de chegada (prioridade dada às gerações futuras, filhos e netos) para a aventura microcreditícia:

\footnotetext{
Na minha infância..., num foi um período muito fácil, porque meus pais, né?,.. somos oito filhos, lá em casa, então teve muita dificuldade pra criar esse oitos filhos, né? (Interlocutora $I$.).

qu'eu fiz de tudo até pra minha filha... minha filha já tá quase se formando, qu'eu acho o estudo primeiro lugar, assim, na vida, é o que você pode deixar de melhor, assim, pro seu filho, né? (Interlocutora $A$.).
} 
(3) A cidadania é secundarizada, seja como mercadoria consumível seja pela contraposição com a necessidade, especialmente nas dimensões da saúde, da educação e do lazer:

descobri que tinha aneurisma, depois fui atrás de tratamento no SUS, não consegui, a sorte que meu marido trabalha no supermercado Cometa, começô a pagar o plano, ai no ano passado eu fiz o meu procedimento, por poco eu num morri, porque Deus num quis, claro, porque tudo o que acontece com a gente é com a permissão de Deus (Interlocutora Z.). [grifo nosso]

Ai foi muita dificuldade a gente quase num estudava, porque num tinha tempo... trabalhava... eu só tenho o quê?, o terceiro ano, só sei assinar o meu nome, pocos... eu leio poco, né?, mas eu sei um poquim, né? [...] Mas dessa família toda, tu acredita que só tem, parece, num tem nenhum que tenha o segundo grau completo, nós somo 14 filho, ninguém tem lá em casa, as otas mais nova, que podia estudá num quiseram, né?, e a gente porque não podia, porque a gente trabalhava muito, tinha muita dificuldade, pra trabalhar pa dá de cumê os mais novo, né?, que tinham...(Interlocutora $K$.). [grifo nosso]

gosto muito de sair (abre um sorriso), gosto de me divertir, né? (abrindo ainda mais o sorriso), gosto de viajar (mantém o sorriso no rosto) [...] [Depois que abriu a loja] Não, não viajei mais, porque a gente fica, assim, muito mais presa, né?, [...], depois da loja eu num... num viajo mais. [...] a gente fica mais presa, né?, devido a loja, mas as festa eu vou sempre (Interlocutora $X$.). [grifo nosso]

(4) A tomada de crédito e o nanonegócio são vistos como uma salvação e como uma possibilidade de sobrevivência, não como uma profissão, uma vez que chegam à informalidade pela falta de alternativas:

A gente num tem muito lucro, mas dá pra ir sobrevivendo, né? (Interlocutora $X$.) [grifos nossos]

Antes do Crediamigo as clientes se autofinanciavam se equilibrando entre o reinvestimento sem capital de giro e o "jogo de cintura” que indissocia o lugar da produção (nanonegócio) e o da reprodução (domicílio): 
Eu pegava assim, eu tinha... eu fazia uma unha, né?, ai eu ali eu comprava... a unha na época era cinco reais, na época que isso já era dinheiro, né?, cinco reais, ai eu pegava e comprava dez reais de esmalte, sabe? [...] era assim qu'eu pegava dinheiro, eu pegava um poquim daqui 'Ah, pa compra a mistura e fazer a feira', era cem reais eu pegava 30 reais e comprava de material, na época, assim, né?, na época eu comprava, ai dava pra mim comprar, ai eu dizia pra ele 'Não...', eu ficava sempre dando aquele... fazendo aquele jogo de cintura pa mim poder ter as coisa (Interlocutora Q.).

A tomada de Crédito (1) modificou as bases de viabilização dos nanonegócios, uma vez que vem desconstruindo a dependência econômica familiar das mulheres para o domicílio e para o nanoempreendimento:

Sempre foi o meu marido que me dava [...] [O Crediamigo] realmente me ajudô muito, né?, porque eu não precisava mais do meu marido (Interlocutora $Z$.).

(2) Centrou as preocupações no pagamento do empréstimo:

As consequência às vezes é, assim, às vezes a gente tem dificuldade, né?, pa pagar, pa arranjar o dinheiro no dia mesmo, porque nem sempre, também... a gente já é revendedora, assim, autônoma, somo autônoma, ai nem sempre a pessoa paga no dia, né?, às vezes a gente tem que tirar do nosso dinheiro pa puder pagar, a dificuldade só é essa, na hora do pagamento (Interlocutora $L$.).

(3) Manteve estagnada tanto a sensação de renda e de consumo, quanto do lugar social do trabalho da mulher (BORN, 2001, p. 251-252):

Não ampliou [renda] não, não vou mentir. [...]. Não [ampliou o consumo e o lazer], ai é que a gente se prende mermo, que a gente tem que trabalhar mais, se for pegar um crediamigo pa tê lazer, como é que você vai ter como você aumentar seu comércio? Né? (Interlocutora I.).[grifo nossos]

A minha profissão, de trabalhar com costura, eu tenho quase certeza que herdei da minha mãe, que minha mãe sempre foi uma grande costureira, né?, e sempre cortava, modelava, 
então iss'aí eu também faço tudo. Graças a Deus! Modelo, corto, costuro, tudo, tudo aqui, quem resolve sou eu (Interlocutora I.). [grifos nossos]

(4) Apresentou a inefetividade da estratégia de desenvolvimento nas vidas:

Pra nós não. Desenvolvimento é pra eles [...]. Mas o desenvolvimento eu não sei, eu acho que nem pra nós que tamo fazendo nem pra eles que tão dando tem desenvolvimento, porque eles tem muita gente que num tá nem vendo, a gente não, a gente nunca pensô em sujar porque tem gente do nome limpo na turma.[...] Eu acho também que o Banco investe muito, mas com medo porque pega muita gente com o nome sujo (Interlocutora $Z$.). [grifo nosso]

Portanto, como resultados da pesquisa encontramos indicações que os participantes, em geral, são pessoas que convivem com a vulnerabilidade e a busca pela sobrevivência, por isso primeiramente se autofinanciam para tornar operativo o impulso das necessidades, dele e da família, por falta de opção. Portanto, priorizam-se os ganhos e relacionase com o contexto de uma cidadania minorada e mercantilizada. É nesse contexto que se encontra com o Crediamigo e acessando ao crédito promove o trabalho em domicílio ao seu autoemprego. Como a maioria dos clientes do programa são mulheres, se evidencia no autoemprego o lugar social da mulher, o relativo "empoderamento" dessa no contexto doméstico e a interdependência no contexto do crédito. A evidência da interdependência é vista tanto no ângulo do grupo de aval solidário que viabiliza e avaliza o acesso ao crédito quanto com relação à política pública. Os participantes são impactados de forma importante em seus nexos subjetivos, seja pela captura de sua subjetividade, seja pela comoditização dos seus laços sociais, e relativamente no contexto objetivo, com a convivência com mais limites que possibilidades. 
Refletidamente, o Crediamigo como política pública se opera por um discurso que tenta balancear o social e o econômico (financeiro), buscando incorporar ao pensamento hegemônico neoliberal massas de pessoas desvinculadas com o poder, mas que podem legitimar o Banco do Nordeste como instituição financeira que pratica uma "capilarização" das atividades de acesso ao crédito. A dissimetria nesta relação se evidencia pelos regramentos e pela dívida imposta no ato de oferta e acesso de um crédito e de uma "bancarização", que de outra maneira seria ainda mais custoso ao participante. De modo que o Crediamigo é um jogo, em que há disputas de interesses. Sendo o maior interesse dos participantes o acesso ao recebimento do dinheiro para a sobrevivência, enquanto da parte da instituição que opera a política pública o maior interesse é a legitimação e a garantia de retorno do empréstimo cedido pela instituição aos participantes.

\section{Considerações finais}

Como apresentado a abordagem narrativa tem potencialidades profundas por agregar em si uma perspectiva tanto hermenêutica quanto participativa, enquanto debate os princípios epistemológicos da pesquisa sociológica e avaliativa. Usá-la como recurso avaliativo de políticas públicas se apresenta com várias possibilidades, uma vez que investigações avaliativas mais contidas podem oferecer tanto um outro ângulo quanto superar as metodologias tradicionais de avaliação. De outro lado, o ponto de vista qualitativo da abordagem narrativa agrega os componentes sociosimbólicos e subjetivos, mas não deixa de lado nem os socioestruturais nem os sociopragmáticos da política pública.

Entretanto, como limites se indica a restrita possibilidade de alargamento na extensão dos sujeitos abarcados pela pesquisa avaliativa com o uso da abordagem narrativa. Uma exceção possível é se usado por 
grupos de pesquisa sociológica e avaliativa, que ainda assim necessitarão de reiterada monitoria. As construções metodológicas mediante os dados podem sofrer vieses, mas se bem orientados e desenhados delinea com vivacidade as realidades encontradas e vividas pelos sujeitos que narram.

A aplicação da abordagem narrativa, tomando como base a noção de trajetória, teve, em campo, ótima recepção por parte das interlocutoras. Isso porque temas financeiros e de renda requerem ângulos de mais proximidade, que a abordagem narrativa prima. Entretanto, por se tratar de um campo que ganha corpo por experiências produtivas e comerciais, as interlocutoras tiveram e impuseram limitações de tempo para a concessão das entrevistas e para quantidades mais largas de encontros. Mesmo assim a noção de trajetória deixou ver um panorama mais amplo, uma vez que mediante as vidas apreendidas se pode desenhar as socio-lógicas a que estão inseridas não só as vidas individuais e grupais (de aval solidário), mas a própria política também.

Por fim, dos indícios que a abordagem narrativa evidenciou sobre a política pública do microcrédito que o Crediamigo sintetiza pontuamos que: esta não pode ser denominada como uma política de microcrédito produtivo solidário orientado, uma vez que se vincula a nanoeconomia, apresentando-se como nanocrédito e muito suscetível a variações macroeconômicas; sua organização não se formula por uma lógica produtiva, sendo mais individualista e atomizada que coletivista ou cooperativa; a orientação também é discutível, já que as relações dos participantes com os assessores de crédito apontaram tanto para a falta de orientação quanto para descontinuidade desta. Além disso, o fato de o Crediamigo ser visto como "estratégia de 'desenvolvimento"” se vincula mais a uma busca e uma estratégia de crescimento e legitimação do próprio Banco do Nordeste do que uma experimentação da parte dos participantes da política pública. 
Assim, a abordagem narrativa apresenta-se como uma caixa de ferramenta ampla e com diversas apropriações específicas. Contem possibilidades extensas de uso e conta com uma perspectiva determinantemente diferenciada para o campo geral de avaliação de políticas públicas. Isso, sem mencionar a associação com o uso da compreensão dos sentidos e significados, clássico das ciências sociais e da sociologia, expostos tanto na atuação das políticas públicas quanto nas narrativas. Como apresentação de resultados, a abordagem se mostra prodigiosa por apontar para respostas avaliativas profundas e por ser econômica no que consiste ao custo da formulação de pesquisas sociológicas e de avaliação.

\section{REFERÊNCIAS}

ALVAREZ, M. C. Florestan Fernandes e Tiago Marques Aipobureu: biografia e sociedade._Tempo Social-Revista de Sociologia da USP, São Paulo, v. 19, n. 2, 2007, p. 289-292.

ARAÚJO, T. P.; LIMA, R. A. Microcrédito ontem e hoje. In.: MATOS, F.; MACAMBIRA, J.; CACCIAMALI, M. C. (Orgs.). A atividade e a política de microcrédito no Brasil: visões sobre sua evolução e futuros desafios. Fortaleza: IDT; USP, 2014, p. 35-53.

BANCO DO NORDESTE. Crediamigo. Disponível em: <www.bnb.gov.br>. Acesso em: 15 jan. 2019. 2019.

BANDEIRA, C. I. A. Microcrédito Emancipatório no Nordeste do Brasil?: estudo de caso do Crediamigo Comunidade nos municípios de Caucaia-CE e Maranguape-CE. Natal, 2008. 116 f. Dissertação (Mestrado em Administração)-Universidade Federal do Rio Grande do Norte, Natal, 2008.

BARREIRA, I. A. F. O legado de Bourdieu na construção de uma sociologia crítica (1930 - 2002). Revista de Ciências Sociais, Fortaleza, v. 33, n. 2, p. 141-144, 2002.

BATISTA, S. H. S. S. Saúde, cuidado e formação: por entre desafios e possibilidades. In: SILVA, V. L. G.; CUNHA, J. L. (Org.). Práticas de 
formação, memória e pesquisa (auto) biográfica. São Paulo: Cultura Acadêmica, 2010, p. 37-44. (Série: artes de viver, conhecer e formar).

BECKER, H. A história de vida e o mosaico científico. In: Métodos de pesquisa em ciências sociais. São Paulo: Hucitec, 1994, p. 101-117.

BERTAUX, D. Los relatos de vida: perspectiva etnosociológica. Barcelona: Bellaterra, 2005.

BONDÍA, J. L. Notas sobre a experiência e o saber de experiência. Revista Brasileira de Educação, Rio de Janeiro, n. 19, p. 20-28, jan./abr, 2002.

BORN, C. Gênero, trajetória de vida e biografia: desafios metodológicos e resultados empírico. Sociologias, Porto Alegre, ano 3, n. 5, p. 240-265, jan./jun., 2001.

BOURDIEU, P. Razões Prática: sobre a teoria da ação. Campinas: Papirus, 1996.

Espaço social e poder simbólico. In: Coisas Ditas. São Paulo: Brasiliense, 2004. p. 149-168.

. Esboço de auto-análise. São Paulo: Companhia das Letras, 2005.

BRANDÃO, C. R. Reflexões sobre como fazer trabalho de campo. Sociedade e Cultura, Goiânia, v. 10, n. 1, p. 11-27, jan./jun. 2007.

CICOUREL, A. Teoria e método em pesquisa de campo. In: GUIMARÃES, A. Z. Desvendando máscaras sociais. 3. ed. Rio de Janeiro: Francisco Alves, 1990, p. 87-122.

DEBERT, G. G. Problemas relativos à utilização da história de vida e história oral. In.: CARDOSO, R. (Org.). A aventura antropológica: teoria e pesquisa. 4. ed. Rio de Janeiro: Paz e Terra, 1986. p. 141-156.

DIMENSTEIN, G. Os “inempregáveis”. Folha de São Paulo, São Paulo, 9 abr. 1997, Mundo. Disponível em: < http://goo.gl/DmWQKZ>. Acesso em: 15 maio 2016.

ELIAS, N. Mozart, sociologia de um gênio. Rio de Janeiro: Zahar, 1995.

ELIAS, N. Mozart: sociologia de um gênio. Rio de Janeiro: Zahar, 1995. Resenha de: BARREIRA, I. A. F. Mozart: sociologia de um gênio. Revista 
Brasileira das Ciências Sociais, São Paulo, v. 11, n. 31, jun., 1996. Disponível em: <https://goo.gl/R6wlqY>. Acesso em: 7 mar. 2017.

DOSSE, F. O desafio biográfico: escrever uma vida. São Paulo: Edusp, 2009.

GARCIA, C. O Desenho do Programa Crediamigo do Banco do Nordeste: inclusão social e mercado. Fortaleza: Banco do Nordeste, 2010. (Série: BNB Teses e Dissertações, n. 21).

GARNICA, A. V. M. Para um mapeamento da formação de professores de matemática no Brasil: considerações sobre a história oral como método qualitativo de pesquisa que envolve oralidade, memória, temporalidade e narrativa. In: SILVA, V. L. G.; CUNHA, J. L. (Org.). Práticas de formação, memória e pesquisa (auto) biográfica. São Paulo: Cultura Acadêmica, 2010. p. 167-188. (Série: artes de viver, conhecer e formar).

GIBBS, G. Análise de dados qualitativos. Porto Alegre: Artmed, 2009. (Coleção: Pesquisa Qualitativa).

GONÇALVES, A. F. Políticas públicas, etnografia e a construção dos indicadores socioculturais. AVAL-Revista Avaliação de Políticas Públicas, Fortaleza, v. 1, n. 1, jan./jun., 2008, p. 17-27.

GOSSELIN, A. S.; MARQUES, K. Etnobiografia, uma etnografia narrativa. In: ALVES, G.; SANTOS, J. B. F. (Orgs.). Métodos e Técnicas de Pesquisa sobre o Mundo do Trabalho. Bauru: Canal 6, 2014. p. 145-159. (Projeto Editorial Praxis).

GUSSI, A. F. Pedagogia da Experiência no Mundo do Trabalho: narrativas biográficas no contexto de mudanças de um Banco Público Estadual. 2004. 347 f. Tese (Doutorado em Educação), Faculdade de Educação, Universidade Estadual de Campinas, Campinas, 2004.

Apontamentos teóricos e metodológicos para a avaliação de programas de microcrédito. AVAL-Revista Avaliação de Políticas Públicas, Fortaleza, v. 1, n. 1, p. 29-37, jan./jun., 2008.

Avaliação de políticas públicas sob uma perspectiva antropológica. In: VALENTE, H. A.D.; PRADOS, R. M. N.; SCHMIDT, C. (Orgs.). A música como negócio: políticas públicas e direitos do autor. São Paulo: Letras e Voz, 2014. p. 19-29. 
KARNANI, A. Microfinance misses its mark. Stanford Social Innovation Review, Stanford, Sum. 2007, p. 34-40.

KOFES, S. Experiências sociais, interpretações individuais: histórias de vida, suas possibilidades e limites. Pagu, Campinas, n.3, p. 117-141, 1994.

. Uma trajetória, em narrativas. Campinas: Mercados de Letras, 2001.

. Uma trajetória em narrativas. Campinas: Mercado das Letras, 2001. Resenha de: SANTOS, B. G. Narrativas: uma trama etnográfica mais sensível. Estudos Feministas, v. 10, n. 1, p. 241-243, jan., 2002.

. "Os papéis de Aspern": anotações para um debate. In:

(Org.). Histórias de vida, biografias e trajetórias. Campinas: UNICAMP, 2004. p. 5-16. (Cadernos do IFCH, 31).

Objetos: trajetória social, política e sentidos. Campos-Revista de Antropologia Social, Curitiba, v. 8, n. 2, p. 27-40., 2007.

LAGNEU-YMONET, P.; MADER, P. O subprime dos pobres? Le Monde Diplomatique. São Paulo, out. 2013. p. 30.

LECHNER, E. Migração, pesquisa biográfica e emancipação social: contributo para a análise dos impactos da pesquisa biográfica junto de migrantes. In: SILVA, V. L. G.; CUNHA, J. L. (Org.). Práticas de formação, memória e pesquisa (auto) biográfica. São Paulo: Cultura Acadêmica, 2010. p. 45-74. (Série Artes de viver, conhecer e formar).

MARTINS, J. S. Vida e história na sociologia de Florestan Fernandes (reflexões sobre o método da história de vida). Revista USP, São Paulo, v. 29, p. 14-19, mar./mai, 1996.

Conclusão: a biografia na experiência da memória. In.:

Uma arqueologia da memória social: autobiografia de um moleque de fábrica. Cotia: Ateliê Editorial, 2011. p. 447-464.

MENDES, F. Abordagem biográfica: reflexões aplicadas a um projeto de pesquisa. In.: KOFES, S (Org.). Histórias de vida, biografias e trajetórias. Campinas: UNICAMP, 2004. (Cadernos do IFCH, 31). p. 235258. 
MONTAGNER, M. A.. Trajetórias e biografias: notas para uma análise bourdiesiana. Sociologias, Porto Alegre, ano 9, n. 17, jan./jul., 2007 p. 240-264.

Biografia coletiva, engajamento e memória: a miséria do mundo. Tempo Social - Revista de Sociologia da USP, São Paulo, v. 21, n. 2, p. 259-282, nov., 2009.

NERI, M. et al. Microcrédito: teoria e prática. In: NERI, Marcelo. (Org.). Microcrédito, o mistério nordestino e o Grameen brasileiro: perfil e performance dos clientes do Crediamigo. Rio de Janeiro: FGV, 2008. p. 2751.

NITSCH, M.; SANTOS, C. A. De Repressão Financeira ao Microcrédito. Revista de Economia Política, Rio de Janeiro, v. 21, n. 4, p. 172-183, out./dez., 2001.

NOBRE, N. (Des)emprego e empreendedorismo: repensar as políticas públicas. Configurações[Online], Braga, n. 10, 2012. Disponível em: < http://journals.openedition.org/configuracoes/1410>. Acesso em: $9 \mathrm{fev}$. 2018.

ORTIZ, R. A procura de uma sociologia da prática. In.: BOURDIEU, P.; ORTIZ, R. (Org.). Pierre Bourdieu: sociologia. São Paulo: Ática, 1983. p. 7-36. (Grandes Cientistas Sociais, 39).

PRATA, M. G. B.. Trabalho de Campo: mitologia, metodologia e autoanálise em uma pesquisa qualitativa sobre "delinquentes juvenis pobres". In.: GONDIM, L. M. P. (Org.). Pesquisa em Ciências Sociais: o projeto da dissertação de mestrado. Fortaleza: UFC, 1999. p. 111-145. (Série: Percursos; 3 ).

RIGOTTO, R. M. Relatos Orais: na encruzilhada entre indivíduo e sociedade em um estudo das representações sociais sobre saúde. In: GONDIM, L. M. P. Pesquisa em ciências sociais: o projeto da dissertação de mestrado. Fortaleza: UFC, 1999. p. 91-110. (Série: Percursos, 3).

RIST, G. El desarollo: historia de una creencia occidental. Madri: Catarata, 2002.

RIVAS FLORES, J. I. Historias de vida y emancipación: subjetividad, conflito y cambio social. Diálogos: Educación y formación de personas adultas, Málaga, v. 3, n. 67-68, p. 5-9, 2011. 
RODRIGUES, L. C. Metáforas do Brasil: demissões voluntárias, crise e rupturas no Banco do Brasil. São Paulo: Annablume; Fapesp, 2004.

- Proposta para uma avaliação em profundidade de políticas públicas sociais. AVAL-Revista Avaliação de Políticas Públicas, Fortaleza, v. 1, n. 1, p. 7-15, jan./jun., 2008.

ROSITO, M. M. B. Pedagogia imaginal: uma narrativa formativa autobiográfica entre os lugares da saúde e da educação. In: SILVA, V. L. G.; CUNHA, J. L. (Org.). Práticas de formação, memória e pesquisa (auto) biográfica. São Paulo: Cultura Acadêmica, 2010. (Série Artes de viver, conhecer e formar). p. 19-35.

SÁ, L. D. Reflexões sobre o trabalho de campo como empreendimento micropolítico. In.: MENDONÇA FILHO, M.; NOBRE, M. T. (Orgs.). Política e afetividade: narrativas e trajetórias de pesquisa. Salvador: EDUFBA; São Cristóvão: EDUFES, 2009. p. 289-310.

SOUSA, D. Proposta de criação do modelo de análise sociológica para políticas públicas (MASPP): justificativa, estrutura e pressupostos. In: ARCOVERDE, A.C. B. (Org.). Dimensões, Interfaces e Práticas de Avaliação de Políticas Públicas. Recife: UFPE, 2014. p. 137-157.

SOUZA, Celina. "Estado do Campo" da pesquisa em políticas públicas no Brasil. Revista Brasileira de Ciências Sociais, São Paulo, v. 18, n. 51, p. 15-20, fev., 2003.

Políticas públicas: questões temáticas e de pesquisa. Caderno CRH, Salvador, v. 16, n. 39, p. 11-24, jul./dez., 2006.

TEIXEIRA, M. A. Microcrédito: condicionantes para saída da condição de pobreza: estudo aplicado ao programa Crediamigo do BNB. 2008. $73 \mathrm{f}$. Dissertação (Mestrado em economia)-Universidade Federal do Ceará, Fortaleza. 2008.

THÉ, R. F. S. Evocações Benebianas: historicidade e propósitos das institucionalidades para o Nordeste. 2014. $100 \mathrm{f}$. Monografia (Bacharelado em Ciências Sociais)-Universidade Federal do Ceará, Fortaleza, 2014.

THÉ, R. F. S.; PEREIRA, J. E. O.; GUSSI, A. F. Experiências Metodológicas de Avaliação: usos da noção de trajetória em políticas públicas. In: Seminário de modelos experiências e avaliação de política, 
programa e projetos, 5, 2014, Recife. Anais . Recife: Universitária da UFPE, 2014. p. 413-430. CD-Rom.

THOMPSON, E. P. A miséria da teoria ou um planetário de erros: uma crítica ao pensamento de Althusser. Rio de Janeiro: Zahar, 1991.

VELHO, G. Subjetividade e sociedade: uma experiência de geração. Rio de Janeiro: Zahar, 1989.

VINUTO, J. A amostragem em bola de neve na pesquisa qualitativa: um debate em aberto. Temáticas, Campinas, v. 20, n. 44, p. 203-220., ago./dez., 2014.

WEBER, F. Trabalho fora do trabalho: uma etnografia das percepções. Rio de Janeiro: Garamond, 2009.

WORTHEN, B. R.; SANDERS, J. R.; FITZPATRICK, J. L. Avaliação de programas: concepções e práticas. São Paulo: Gente, 2004. 